\title{
MANFAAT PEMBERIAN MANUAL TERAPI DAN CODMAN PENDULAR EXERCISE TERHADAP AKTIVITAS FUNGSIONAL PASIEN FROZEN SHOULDER
}

\section{Isidorus Jehaman ${ }^{1}{ }^{*}$, Sabirin Berampu ${ }^{1}$, Redi Tantangan $^{1}$, Timbul Siahaan ${ }^{1}$, Simson Sinuhaji ${ }^{1}$}

\author{
${ }^{1}$ Program Studi Fisioterapi S1, FKF Institut Kesehatan Medistra Lubuk Pakam
}

\author{
JIn. Sudirman No.38 Lubuk Pakam, Kabupaten Deli Serdang, \\ Sumatera Utara - Indonesia \\ *email korespondensi author: dorusman1976@gmail.com
}

DOI $10.35451 / j p k . v 1 i 1.702$

\begin{abstract}
Abstrak
Gangguan pada daerah bahu yang dapat menimbulkan masalah fisik maupun fungsional sering disebut frozen shoulder. Problematik yang sering terjadi adalah nyer, keterbatasan gerak sendi, dan ketebatasan aktifitas fungsional, seperti menjangkau barang yang letaknya lebih tinggi dari baru, atau pada saat mangangkat dan membawa barang. Untuk mengatasi problem tersebut fisioterapi tindakan yang dapat diberikan adalah manual terapi dan codman pendular exercise. Tujuannya untuk mengetahui manfaat manual terapi dan codman pendular dalam peningkatan aktivitas fungsional pasien frozen shoulder di Rumah Sakit Grandmed Lubuk Pakam Tahun 2019. Metode manual terapi dan codman pendular yang diberikan kepada 24 orang pasien di Poli Fisioerapi Rumah Sakit Grandmed Lubuk Pakam. Alat ukur yang digunakan untuk mengukur kemampuan aktivitas fungsional bahu adalah shoulder agony and incapacity record dengan kategori 0\%-60\% adalah Membaik dan 61\%$100 \%$ adalah memburuk. Berdasarkan hasil yang diperoleh selama melakukan tindakann manual terapi dan codman pendular menunjukan bahwa kemampuan aktivitas fungsional bahu pasien mengalami peningkatan. diamana manual terapi dan codman pendular exercise dari 16 sampel nilai kemapuan aktivitas fungsionsal bahu dengan nilai SPADI 100\% memburuk dan sesudah tindakan manual terapi dan codman pendular exercise selama 3 kali turun menjadi $12.5 \%$ memburuk dan $87.5 \%$ membaik. Berdasarkan information tersebut dapat disimpulkan bahwa ada pengaruh pemberian manual terapi dan codman pendular exercise dalam Peningkatkan aktivitas fungsional bahu pasien sebesar $87.5 \%$.
\end{abstract}

Kata kunci: manual terapi dan codman pendular exercise, aktivitas fungsional

\begin{abstract}
Background: Frozen shoulder is a joint disorder that causes limited motion of the Disorders of the shoulder area that can cause physical or functional problems are often called frozen shoulder. Problems that often occur are pain, limited joint motion, and limitations in functional activities, such as reaching items that are higher than new, or when lifting and carrying items. To overcome this problem, physiotherapy measures that can be given are manual therapy and codman pendular exercise. The aim is to find out the benefits of manual therapy and codman pendular in increasing the functional activity of frozen shoulder patients at Grandmed Lubuk Pakam Hospital in
\end{abstract}


2019. Manual therapy methods and codman pendular were given to 24 patients at the Physiotherapy Clinic at Grandmed Lubuk Pakam Hospital. The measuring instrument used to measure the ability of the functional activity of the shoulder is the Shoulder agony and incapacity record with categories 0\%-60\% is improving and $61 \%-100 \%$ is worsening. Based on the results obtained during manual therapy and codman pendular, it shows that the ability of the patient's shoulder functional activity has increased. where manual therapy and codman pendular from 16 samples of shoulder functional activity scores with SPADI values of $100 \%$ worsened and before manual therapy and codman pendular for 3 times decreased to $12.5 \%$ worsened and $87.5 \%$ improved. Based on this information, it can be said that there is an effect of manual therapy and pendular kodman in increasing the patient's shoulder functional activity by $87.5 \%$.

Keywords: manual therapy and codman pendular exercise, functional activitie

\section{Pendahuluan}

Frozen shoulder merupakan salah satu kasus yang sering menimbulkan masalah nyeri dan keterbatasan gerak sendi bahu baik secara aktif maupun pasif. Sendi bahu memiliki peran penting dalam kegiatan manusia, sehingga bila ada gangguan pada sendi bahu akan mengganggu aktivitas manusia (Mujianto, 2013, Durall, C.,2011). Frozen shoulder dapat menimbulkan masalah yang komplek daripada tendinitis dan bursitis, karna terjadi keterbatasan gerak yang lebih berat dan tingkat kesembuhan yang lebih buruk dibandingkan dengan tendinitis dan bursitis (Miharjanto, dkk, 2010, dan Christy. (2010).

Secara epidemologi kejadian frozen shoulder terjadi antara usia 40-60 tahun. Dari $2-5 \%$ populasi sekitar $60 \%$ dari kasus Frozen shoulder lebih banyak mengenai perempuan dibanding lakilaki. Frozen shoulder juga terjadi pada $10-20 \%$ dari penderita diabetes melitius merupakan salah satu faktor resiko frozen shoulder (Mujianto, 2013).

Menurut American Academy of Orthopedic Surgeons (AAOS) Tahun 2014 Keluhan tentang masalah pada bahu tercatat dirasakan 0,9\% hingga $2,5 \%$ yang dialami oleh setiap individu dengan tingkatan usia yang beragam dengan data kenaikan jumlah orang yang mengalami keluhan bahu rata-rata sebesar 6,9\% hingga 26\%, kenaikan setiap 1 bulan rata-rata sebesar 18,6\% hingga $31 \%$, kenaikan $4,7 \%$ hingga $46,7 \%$ setiap tahunnya, dan kenaikan rata-rata untuk beberapa tahun sebesar $6,7 \%$ hingga $66,7 \%$. Keluhan bahu juga sering terjadi dalam dunia kerja. Organisasi Persatuan Pekerja di Provinsi Ontario, Kanada mencatat bahwa keluhan bahu yang dirasakan oleh para pekerja adalah sebesar $6,1 \%$ ( $\mathrm{n}=$ 5.786) selama tahun 2009. Penelitian lain menyebutkan bahwa sekitar $21 \%$ dari pasien mengalami kesembuhan setelah menjalani perawatan selama 6 bulan, dan sebesar $49 \%$ mengalami kesembuhan setelah 18 bulan.

Prevalensi Frozen shoulder dari tahun ke tahun terus meningkat ,di Inggris $14 \%$, di Belanda $12 \%$ dan di Indonesia hampir $5 \%$ dari penduduk yang mengalami Frozen shoulder (Miharjanto dkk, 2010). Berdasarkan hasil penelitian di RSUP Wahidin Sudirohusada makasar pada tahun 2007 tercatat dari 360 orang yang dirujuk ke poli fisioterapi, $11,67 \%$ menderita frozen shoulder. Pada tahun 2009 
Received: 27 May 2021 :: Accepted: 24 June 2021 :: Published: 30 June 2021

pasien Frozen shoulder meningkat menjadi 587 orang, Pada tahun 2010 pasien Frozen shoulder meningkat sebanyak 370 orang (Miharjanto dkk, 2010).

Berdasarkan hasil observasi awal di Rumah Sakit Grandmed Lubuk Pakam, peneliti memperoleh information dari poli fisioterapi tahun 2019 yang mengalami gangguan Frozen shoulder sebanyak 25 orang dalam bulan maret 2019 dengan problem adanya nyeri, keterbatasan gerak dan gangguan aktifita fungsional. Intervensi yang digunakan untuk mengatasi problem tersebut yaitu holdpack, interferential treatment, ultrasound, manual therapy, exercise therapy. Salah satu modalitas yang dapat diberikan untuk meningkatkan aktivits fungsional pada kasus Frozen shoulder adalah manual terapi dan codman pendular exercise.

Terapi manipulasi adalah salah satu metode yang dilakukan dengan gerakan pasif dan tiba-tiba, amplitudo kecil dan kecepatan yang tinggi, sehingga pasien tidak mampu menghentikan gerakan yang terjadi (Mudatsir, 2012). Tujuan manual terapi sendi adalah untuk mengembalikan fungsi sendi ordinary dan untuk memperbaiki joint play development (Kuntono, 2009). Pemberian teknik manipulasi Latero ventro cranial akan membantu memulihkan keterbatasan gerak dan membantu memfasilitasi joint play development pada sendi bahu (Mujianto, 2013). Hasil penelitian Munn et al tahun 2009 menmukan bahwa latihan manual terapi mampu meningkatkan lingkup gerak sendi pada penderita frozen shoulder, sehingga dapat diberikan pada kasus ini.

Codman pendular exercise merupakan intervensi yang sering digunakan oleh fisioterapis untuk meningkatkan LGS pada pasien frozen shoulder. Pada saat latihan ini dilakukan otot-otot sendi bahu tidak berkontraksi atau rileksasi sehingga saat melakukan gerakan tidak menimbulkan nyeri. Codman Pendular Exercise tidak hanya bisa dilakukan di rumah sakit tetapi latihan ini juga dapat dilakukan di rumah sebagai edukasi untuk meningkatkan aktivitas fungsionalnya. Menurut hasil penelitian Neumann et al, 2010 bahwa pemberian codman pendular exercise mampu meningkatkan LGS. Berdasarkan penelitian terdahulu oleh Salim tahun 2013 tentang penambahan codman pendular exercise kepada beberapa pasien Frozen shoulder menunjukan hasil dimana ROM sendi glenohumeral dan kemampuan fungsional pada bahu dapat meningkat. Berdasarkan latar belakang masalah diatas, maka penulis akan meneliti tentang pengaruh teknik manipulasi dan codman pendular exercise terhadap kemampuan fungsional bahu pasien Frozen shoulder menggunakan indeks SPADI. Untuk mengetahui Pengaruh Pemberian manual terapi Dan Codman Pendular Exercise Terhadap Peningkatan Aktivitas Fungsional Pada Pasien Frozen Shoulder Di Rumah Sakit Grandmed Lubuk Pakam Tahun 2019.

Tujuan yang ingin dicapai dalam kegiatan ini adalah untuk mengetahui manfaat pemberian manual terapi dan codman pendular exercise dalam meningkatkan aktivitas fungsional bahu pada pasien akhibat frozen shoulder. Sedangkan Manfaat kegiatan adalah 1) Bagi Pasien; Setelah mendapatkan tindakan terapi dengan manual terapi dan codman pendular exercise dapat meningkatkan kemampuan aktivitas fungsional bahu. 2) Bagi Institusi Pendidikan; Sebagai tambahan keilmuan tentang pengaruh pemberian teknik manual terapi dan Codman pendular pada kasus Frozen Shoulder, 3) Bagi Institusi Pelayanan; untuk menjadi referensi dalam pemberian tindakan fisioterapi pada pasien frozen shoulder khususnya pasien yang 
Received: 27 May 2021 :: Accepted: 24 June 2021 :: Published: 30 June 2021

mengalami gangguan aktivitas

fungsional, 4) Bagi para Peneliti; Sebagai bahan masukan bagi siapa saja yang melakukan kegiatan yang sama bagi para peneliti untuk melakukan kajian lebih menalam dan komprehensif mengenai tindakan manual terapi dan codman pendular exercise dalam meningkatkan kemampuan aktivitas fungsional pada pasien frozen shoulder.

\section{Metode}

\section{a. Permasalahan}

Permaslahan yang terjadi akhibat frozen shoulder dapat berupa, 1) Nyeri, 2) Keterbatasan Lingkup gerak sendi; 3) Penurunan Kekuatan otot; 4) Gangguan aktifitas fungsional seperti mengangkat tangan ke atas waktu menyisir rambut, menggosok punggung sewaktu mandi, mengambil sesuatu dari saku belakang celana, mengambil atau meletakkan sesuatu di atas dan kesulitan saat memakai dan melepas baju. Hal ini akan menyebabkan pasien tidak menggerakkan sendi bahunya yang akhirnya dapat memperberat kondisi yang ada sehingga dapat menimbulkan gangguan gerak dan aktivitas fungsional keseharian (Habermeyer, Peter, 2009).

\section{b. Metode Yang Ditawarkan}

Metode yang akan ditawarkan dalam program ini adalah memberikan manual dan codman pendulum yang bermanfaat bagi kesehatan fisik dan fungsional lansia. Penerapan metode ini melibatkan pasien yang teridentifikasi adanya keterbatasa melakukan aktivitas fungsional bahu pada pasien frozen shoulder di poli Fisioterapi di Rumah Sakit Grandmed Lubuk Pakam. Program ini dilakukan pada bulan Januari-Mei 2021 dengan jumlah pasien 16 orang. Tindakan manual dan codman pendulum ini diberikan selama $3 x$ terapi dengan waktu masing-masing tindakan 15-20 menit.

\section{Hasil dan Pembahasan}

Berdasarkan hasil pengukuran nilai SPADI sebelum dilakukan pemberian manual terapi dan codman pendular exercise terhadapa aktivitas fungsional pasien bahwa dari jumlah 16 sampel yang memiliki nilai aktivitas fungsional 0\%-60\% (memburuk) sejumlah 2 orang $(20,5 \%)$, dan yang memiliki nilai aktivitas fungsional $61 \%-100 \%$ (membaik) sejumlah 14 orang $87,5 \%$. Berdasarkan information tersebut dapat disimpulkan bahwa ada pengaruh pemberian manual terapi dan codman pendular dalam Peningkatkan aktivitas fungsional bahu pasien frozen shoulder.

Kelley et al, 2009 berpendapat bahwa frozen shoulder merupakan istilah yang digunakan untuk semua gangguan pada sendi bahu yang menimbulkan nyeri dan pembatasan lingkupan gerakan tersebut. Menurut American Academy of Orthopedic Surgeons (AAOS) faktor predisposisi frozen shoulder anatara lain: immobilisasi lama, injury, over use, wounds, operasi pada sendi, hipertitoidisme, penyakit kardiovaskuler dan melancholy.

Faktor predisposisi frozen shoulder dapat berupa posisi diam dalam waktu dalam waktu lama, penggunaan yang berlebihan, faktor cedera dan pascaoperasi sendi. Adanya Posisi diam dan menetap sendi bahu dalam waktu yang lama dapat menyebabkan perlengketan sendi intra articular. Hal tersebut berpengaruh secara signifikan terhadap nyeri dan kekakuan sendi glenohumeral (Miharjanto dkk, 2010, Varcin, L. 2013 dan Cluett, 2014, ).

Peningkatan kemampuan melakukan aktivitas fungsional bahu terjadi oleh karena terapi manipulasi merupakan metode terapi yang gerakan oleh orang lain dengan tiba-tiba, amplitudo kecil dan kecepatan yang tinggi, sehingga pasien tidak mampu menghentikan gerakan yang terjadi (Mudatsir, 2012, dan Donatelli, Robert. 
Received: 27 May 2021 :: Accepted: 24 June 2021 :: Published: 30 June 2021

A. 2012). Secara mekanis, tujuannya maual terapi yakni memperbaiki joint play pada sendi bahu sehingga mampu memperbaiki keterbatasan sendi baik secara passive maupun secara aktif. Terapi manipulasi harus diakhiri apabila sendi telah mencapai LGS maksimal tanpa nyeri dan pasien dapat melakukan gerakan aktif dengan ordinary (Kuntono, 2009). Terapi manipulasi terbukti berpengaruh terhadap dalam mengatasi nyeri dan keterbatasan sendi (Mudatsir, 2012). Hal tersebut dapat mengembalikan fungsi sendi ordinary dan tanpa nyeri sehingga menyebabkan aktivitas fungsional pasien akan meningkat. Setelah dilakukan pemberian terapi manipulasi dilanjutkan dengan Codman Pendular Exercise. Tenik ini dilakukan secara passive dengan menggerakkan sendi bahu. Mekanisme pengurangan nyeri dan peningkatan aktivitas fungsional bahu dengan Codman Pendular Exercise diperoleh melalui distraksi (pengaruh gravitasi) dan osilasi, serta adanya peningkatan nutrisi pada permukaan sendi, sehingga mempermudah mobilisasi sendi, meningkatkan ekstensibilitas kapsul sendi glenohumeralis pada penderita frozen shoulder. Gaya gravitasi menyebabkan capitas glenoidalis dan caput humeri meregang sehingga tidak terjadi gesekan antara capitas glenoidalis dan caput humeri. Codman Pendular Exercise tidak hanya bisa dilakukan di rumah sakit tetapi latihan ini juga dapat dilakukan di rumah sebagai edukasi untuk meningkatkan aktivitas fungsionalnya.

Hasil penelitian Salim 2013, tentang latihan codman pendular kepada beberapa pasien Frozen shoulder menunjukan bahwa ROM sendi bahu dan kemampuan aktiitas fungsional pasien mengalami meningkat. Terapi manipulasi dan codman pendular dapat digunakan untuk pasien frozen shoulder karena kedua metode ini dapat mengurangi perlengketan pada kapsul sendi glenohumeral. Jika perlengketan pada kapsul sendi berkurang maka ketebatasan gerak pada pasien akan menurun sehingga luas gerak sendi akan meningkat dan aktivitas fungsional juga akan meningkat. Intervensi codman pendular efektif untuk membantu pasien frozen shoulder, karena gerakan yang mudah dilakukan dan saat melakukan gerakan pasien tidak merasakan nyeri karna gerakan codman pendular menggunakan gaya gravitasi. Gaya gravitasi menyebabkan capitas glenoidalis dan caput humeri meregang sehingga tidak terjadi gesekan antara capitas glenoidalis dan caput humeri. Jika dilihat dari segi ekonomi konomi kedua Latihan dapat membantu karna codman pendular exercise bukan hanya dapat dilakukan di rumah sakit tetapi latihan dapat dilakukan pasien dirumah sebagai home program.

\section{Kesimpulan}

Berdasarkan evaluasi hasil pengukuran altivitas fungsional dengan SPADI dan pembahasan diatas maka dapat disimpulkan bahwa dari 16 pasien yang diterapi kemampuan aktivitas fungsional pasien sebelum terapi seluruhnya berada pada ranges 0-60\% dengan kategori buruk. Tetapi setelah dilakukan tindakan fisioterapi dengan manual terapi dan codman pendular dari 16 pasien terdapat 14 orang atau $87,5 \%$ kemampuan aktivitas fungsionalnya berada pada ranges 61$100 \%$ (kategori membaik atau terjadi pengingkatan) dan 2 orang atau 12,5\% kemampuan aktivitas fungsionalnya berada pada ranges $0-60 \%$ (kategori memburuk atau belum menunjukkan ada Peningkatan). Berdasarkan information tersebut dapat disimpulkan bahwa ada pengaruh pemberian manual terapi dan codman pendular dalam 
meningkatkan kemampuan fungsional bahu pada pasien frozen shoulder sebesar $87,5 \%$

\section{Ucapan Terima Kasih}

1. Kepada semua subjek yang telah bersedia untuk menjadi subjek kegiatan PKM ini.

2. Direktur RS Grandmed Lubuk Pakam yang telah memberikan ijin untuk melaksanakan kegiatan ini.

3. Rektor Institut Kesehatan Medistra Lubuk Pakam yang telah memberikan dukungan dana dan fasilitas agar penelitian dapat terlaksana dengan baik dan lancar.

\section{Daftar Pustaka}

AAOS. (2007). Frozen Shoulder. American Academy of Orthopaedic. Diakses tanggal 17 Oktober 2014, dari. http://orthoinfo.aaos.org/topic.cf m?topic $=a 00071$

Christy. (2010). Functional anatomy, musculoskeletal anatomy, kinesiology, and palpation for manual therapists. Philadelphia: Lippincott Williams \& Wilkins.

Cluett. (2014). Frozen Shoulder. Diakses: 12 Oktober 2014. Dari http://orthopedics.about.com/cs/fr ozenshoulder/a/frozenshoulder.ht $\mathrm{ml}$

Donatelli, Robert. A. (2012). Physical therapy of the shoulder 5th edition. St Louis. Missouri: Elsevier.

Durall, C. (2011). Adhesiva Capsulitis. In: Brotzman, S.B., Manske, R.C., editors. Clinical Orthopedic Rehabilitation: an evidence-based. second edition. Philadelphia: Elsevier.

Habermeyer, Peter. (2009). Classification And Scores of The Shoulder. Germany: Springer Berlin.

Kelley, Martin. J dan Clure M,C,. (2009). Frozen shoulder evidence and a proposed model guiding rehabilitation. Journal of orthopaedic and sport physical therapy.39(2).

Kelley, MJ,. et al. 2013. Shoulder Pain and Mobility Deficits: Adhesive Capsulitis.

Kuntono, H. P. (2009). Aspek Fisioterapi Syndroma Nyeri Bahu. Disampaikan dalam Kupas Tuntas Frozen Shoulder, Surabaya, hal. 39.

Miharjanto, Hadi., Kuntono, H. P., dan Setiawan D. (2010). Perbedaan Pengaruh Antara Latihan Konvensional Ditambah Latihan Plyometrics dan Latihan Konvensional Terhadap Pengurangan Nyeri, dan Disabilitas Penderita Frozen Shoulder. Phedheral Vol. 3. No. 2.

Mound. (2012). A Systematic Review And Cost-Effectiveness Analysis. Management of Frozen Shoulder. Vol 16.

Mudatsir, S. (2012). Terapi Masipulasi Ekstremitas, Pelatihan Manual Terapi.Surakarta.

Mujianto. (2013). Cara Cepat Mengatasi 10 Besar Kasus Muskuloskeletal dalam Praktik Klinik Fisioterapi. Jakarta: CV. Trans Info Media.

Munn et al., 2009. The effectiveness of manual therapy in the management of musculoskeletal disorders of the shoulder: A systematic review.

Neumann D. (2009). Essentials Of Kinesiology For The Physical Therapist Assistant. Philadelphia: Mosby Affiliateof Elsevier Science.

Salim, Johanes Surya. (2013). Penambahan Teknik Manual Therapy Pada Latihan Pendular Codman Lebih Meningkatkan Lingkup Gerak Sendi pada Sendi Glenohumeral Penderita Frozen Shoulder. (Thesis). Denpasar: Universitas Udayana.

Varcin, L. (2013). Unlocking Frozen Shoulder New Paradigm of Treatment. Balboa. 